\title{
Three-Dimensional Craniofacial Features of Glut1 Deficiency Syndrome Patients
}

\author{
Valentina PUCCIARELLI ${ }^{1}$, Marina CODARII ${ }^{1}$, Chiara INVERNIZZI ${ }^{1}$, \\ Simona BERTOLI ${ }^{2}$, Alberto BATTEZZATI', Ramona DE AMICIS ${ }^{2}$, \\ Valentina DE GIORGIS ${ }^{3}$, Pierangelo VEGGIOTTI ${ }^{3,4}$, Chiarella SFORZA ${ }^{1 *}$ \\ ${ }^{1}$ Dipartimento di Scienze Biomediche per la Salute, Università degli Studi di Milano, Milano, Italy; \\ ${ }^{2}$ Dip. Scienze per gli Alimenti, la Nutrizione e l'Ambiente, Università degli Studi di Milano, Milano, Italy; \\ ${ }^{3}$ Dept. Child Neurology and Psychiatry, C. Mondino National Neurological Institute, Pavia, Italy; \\ ${ }^{4}$ Brain and Behaviour Department, University of Pavia, Pavia, Italy
}

DOI: 10.15221/15.061 http://dx.doi.org/10.15221/15.061

\begin{abstract}
Glut1 deficiency syndrome is a neurological disease due to impaired glucose transport across blood brain barrier. The disease is consequence of mutations on gene SCL2A, encoding for protein GLUT1, which is responsible for glucose facilitated diffusion from intracellular to extracellular compartment. Mutations of this gene lead to a syndrome characterised by infantile seizures, developmental and cognitive delay, movement disorders, microcephaly and hypoglicorrachia. Currently, the diagnosis of this condition is clinical and genetic, but the recognition of some craniofacial features typical of the patients, and easily observable during a routine medical evaluation, could be of great help for an early diagnosis. In order to characterise the phenotype of Glut1 deficiency syndrome (Glut1-DS) patients and improve the diagnosis of the disease, a three-dimensional assessment of soft tissue facial features was made using stereophotogrammetry. We studied 7 patients with Glut1-DS. The threedimensional coordinates of a set of standardised landmarks, previously identified on the face and then digitized on the three-dimensional facial reconstructions, were collected and used to calculate anthropometric linear distances and angles. Z scores, obtained comparing patients with healthy reference subjects, matched for gender, age and ethnicity, were used for comparisons. Results showed that Glut1-DS patients have a set of common craniofacial features; most of the anomalies were found in the mandible. Glut1-DS patients seem to have a more anterior chin; their mandibular body is longer but the rami are shorter, with a reduced gonial angle. Data can be of great interest to improve the diagnosis of this syndrome and to allow longitudinal evaluations of facial morphology in a safe and not invasive way. Nevertheless further evaluation on a larger sample is advised.
\end{abstract}

Keywords: Glut-1 deficiency syndrome, stereophotogrammetry, face

\section{Introduction}

Recognised by De vivo et al. in 1991, Glut1 deficiency syndrome (Glut-1DS) is a neurological disorder characterised by a defective transport of glucose across blood brain barrier [1-4]. Glucose is an essential substrate, in particular for brain. In adults, $20 \%$ of glucose is used for brain metabolism, whereas in children the brain uses up to $80 \%$ of whole available glucose $[5,6]$.

Glucose transporter type 1 (GLUT1), encoded by SCL2A gene (1p35-31.3), is responsible for facilitated transport of glucose across blood brain barrier. Mutations on the gene, mostly transmitted as autosomal dominant traits, impair its function, leading to a syndrome whose hallmarks are low levels of glucose in cerebrospinal fluid within the context of normoglycaemia [3,7].

The phenotype of Glut-1DS patients includes epileptic seizures and movement disorders, especially ataxia and spasticity. Furthermore, patients are characterised by developmental delay. All these features may be more or less serious, with different degrees of impairment. Patients can also have language problems and speech can be delayed $[4,8]$.

Currently, patient's symptoms can be partially controlled through a ketogenic diet, which is necessary to mimicry the fasting state. During fast, in fact, the brain must use an alternative energy resource, which is represented by ketones, since glycogen storage finishes in minutes. Ketones, indeed, are a good alternative to glucose because they are transported into the brain through a different transporter, making ketogenic diet a good therapeutic option for keeping seizures under control $[9,10]$.

For what concerns diagnosis of Glut-1DS patients, it is nowadays based on the mutational analysis of the SCL2A gene or through the analysis of the cerebrospinal fluid (CSF), which will show a condition of low glucose levels, despite normal levels in the blood [11].

* chiarella.sforza@unimi.it; +39 02503 15387; www.scibis.unimi.it 
Additionally, patients may also present some alterations in their craniofacial aspect $[1,8]$. One of the most common findings is microcephaly, which depends on the severity of the disease [12].

To the best of our knowledge, no detailed quantitative investigations of craniofacial morphology of Glut-1DS patients have been published, even if a recent clinical report made on Italian GLUT1-DS patients found facial alterations in $18 \%$ of analyzed subjects, who had prognathism (a more advanced mandible relative to the maxilla, corresponding to a Class III maxillo-mandibular relationships) [8]. The authors suggested that prognathism could be a possible gestalt sign of the disease.

Indeed, a particular facial morphology is characteristic of different syndromes, and its quantitative assessment can help in diagnosis [13-15]. For instance, subjects with Down syndrome show a unique facial appearance; among the other alterations, there is a particular morphology of the ears, which result smaller than in normal subjects. This feature can be appreciated even before birth, through the use of ultrasonography $[16,17]$. Moebius syndrome patients have a more prominent and hyperdivergent face in the sagittal plane, smaller mandibular dimensions with a tendency towards a Class II maxillo-mandibular relationships (maxillary protrusion associated with mandibular retrusion) [18]. Ectodermal dysplasia patients have maxillary and mandibular hypoplasia, a Class III tendency with flat or concave facial profile, and a more disharmonious face than controls [19].

All these features can be appreciated using anthropometry, that allows the not-invasive, threedimensional study of facial morphology in vivo. Classic anthropometry (using callipers and protractors) has been successfully replaced by digital anthropometry, where various optical instruments can detect and record the facial characteristics without submitting the subjects to painful and potentially dangerous examinations [11,12,20-23]. A quantitative assessment of the facial characteristics of a given patient relative to those of a group of control subjects matched for sex, age and ethnicity, can offer valuable information that can direct the clinician towards more complex, expensive and invasive evaluations.

In the current pilot study we performed a three-dimensional evaluation of the facial soft tissues of a group of Italian Glut-1DS patients using a stereophotogrammetric device. The clinical and genetic features of these patients had been recently described [8]. We wanted to investigate the possible presence of common facial alterations that may be used as "soft" markers of Glut-1DS.

\section{Method}

\subsection{Patients and reference subjects}

Seven patients (6 females, 1 male) with GLUT1-DS were included in this study. Reference subjects, matched with patients for ethnicity, gender and age, were also examined (319 females and 71 males). Details of the analyzed patients and subjects are shown in Table 1. All reference subjects did not have a previous history of facial trauma, surgery or other anomalies.

Before the three-dimensional acquisition of the face, the procedure was illustrated and all involved subjects gave their written consent to it. For subjects under 18 years of age, written consent was given by the parents or legal guardians, and oral consent by the subjects themselves. The procedure, which was safe and not invasive, did not imply any risk for the subjects, respected the tenets of the Declaration of Helsinki and had obtained the approval of the local ethic committee.

Table 1. Patients included in the study and number of corresponding reference subjects used for comparisons.

\begin{tabular}{|c|c|c|c|}
\hline & gender & age (years) & \# of reference subjects \\
\hline patient \#1 & female & 27 & 187 \\
\hline patient \#2 & female & 18 & 187 \\
\hline patient \#3 & female & 8 & 45 \\
\hline patient \#4 & female & 8 & 45 \\
\hline patient \#5 & female & 13 & 37 \\
\hline patient \#6 & female & 3 & 50 \\
\hline patient \#7 & male & 38 & 71 \\
\hline
\end{tabular}

\subsection{Data collection and analysis}

We performed data collection using a stereophotogrammetric system, VECTRA M3 (Canfield Scientific Inc, Fairfield, USA). The instrument has a $1.2 \mathrm{~mm}$ geometry resolution and can reproduce three-dimensional facial morphology with a capture time of 3.5 milliseconds. 
Before the stereophotogrammetric acquisition of the face, an experienced operator marked the face of all patients and reference subjects with a set of 50 standardized landmarks (1 $\mathrm{mm}$ diameter). Landmarks were drawn with a washable and skin-compatible make up eyeliner and were distributed on the face, orbits, nose, lips and mouth $[22,23]$. During the procedure, the subjects sat relaxed and in a position suitable for facial landmarks identification. Their facial pictures were then obtained, and the system reconstructed the three-dimensional position of facial features.

Among the complete set of 50 landmarks, 12 were selected, including midline and paired landmarks. All landmarks were identified on the three-dimensional reconstruction of the face, their coordinates were extracted and a set of measurements was calculated [24].

Landmarks used in this study and their description are reported in Table 2, while Figure 1 shows their position on the face [22].

Table 2. Landmarks used in this study.

\begin{tabular}{|l|l|l|}
\hline Abbreviation & Landmark & Description \\
\hline $\mathbf{T r}$ & Trichion & In the hairline in the middle of the forehead \\
\hline $\mathbf{N}$ & Nasion & At the suture between forehead and nose \\
\hline $\mathbf{P r n}$ & Pronasale & The most prominent point in the nose \\
\hline $\mathbf{S n}$ & Subnasale & At the end of the columella \\
\hline $\mathbf{L s}$ & Labiale superius & In the midline between upper lip and skin \\
\hline $\mathbf{S I}$ & Sublabiale & In the midline between lower lip and skin \\
\hline $\mathbf{P g}$ & Pogonion & The most prominent point in the chin \\
\hline $\mathbf{C h}$ & Cheilion & Outer labial commissura \\
\hline $\mathbf{E x}$ & Exocanthion & Outer commissura of the eye \\
\hline $\mathbf{Z y}$ & Zygion & The most prominent point in the zygomatic arch \\
\hline $\mathbf{T}$ & Tragion & In the middle of the tragus \\
\hline $\mathbf{G o}$ & Gonion & At the mandibular angle \\
\hline
\end{tabular}

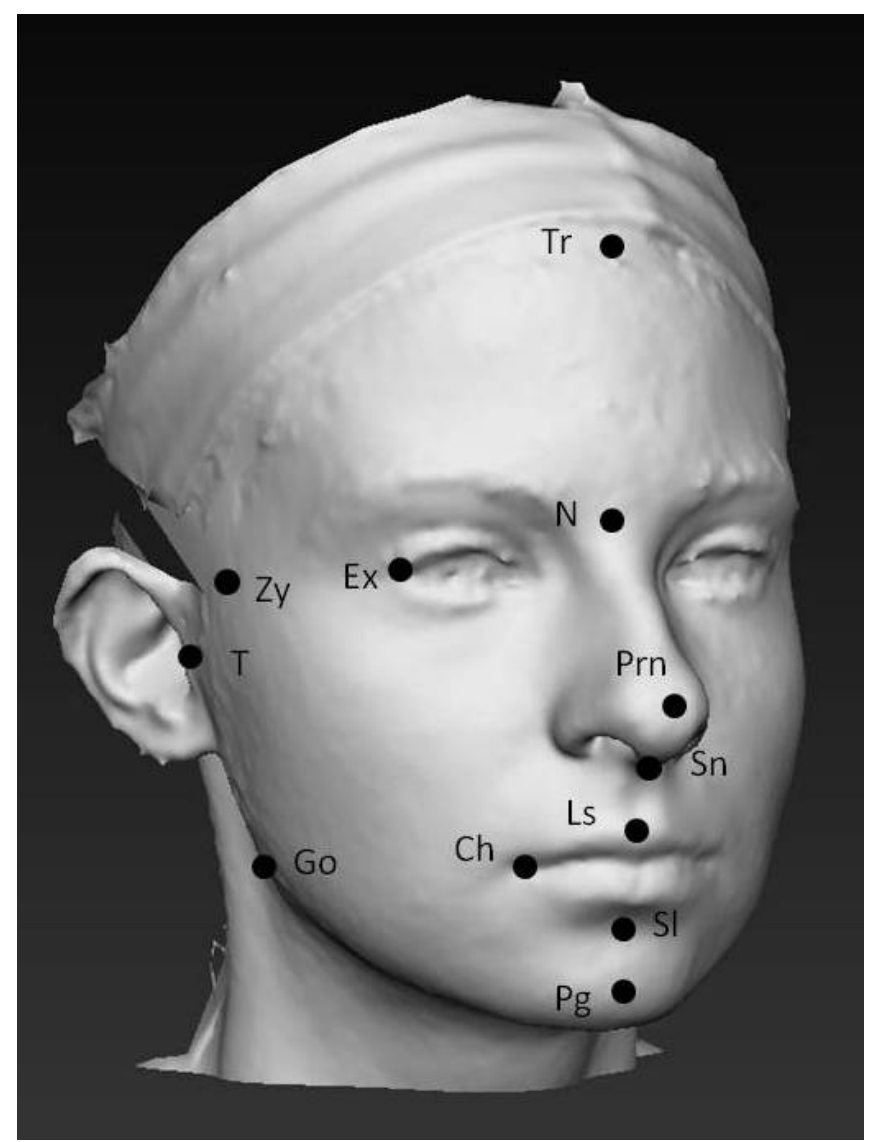

Fig. 1. Landmarks digitized on all the subjects. 
For each subject a set of nine linear distances, one linear distances ratio and nine angular measurements was considered. Linear distances were expressed in millimetres, the ratio in percentage and the angles in degrees. Table 3 shows the performed measurements.

Table 3. Linear and angular measurements performed; $r$ and I indicate right and left side.

\begin{tabular}{|c|c|c|c|}
\hline Distance & Description & Angle & Description \\
\hline Tr-N & Length of the upper third of the face & N-Sn-Pg & Facial convexity, except nose \\
\hline N-Sn & Length of the middle third of the face & SI-N-Sn & Cutaneous ANB \\
\hline Sn-Pg & Length of the lower third of the face & $\mathrm{T}_{\mathrm{r}}-\mathrm{N}-\mathrm{T}_{\mathbf{I}}$ & Upper facial convexity \\
\hline$E x_{r}-E x_{1}$ & Biocular width & $T_{r}-$ Prn- $T_{1}$ & Middle facial convexity \\
\hline$T_{r}-T_{1}$ & Skull base width & $\mathrm{T}_{\mathrm{r}}-\mathrm{Pg}-\mathrm{T}_{1}$ & Lower facial convexity \\
\hline $\mathrm{Go}_{\mathrm{r}}-\mathrm{Go}_{1}$ & Mandibular width & Sn-N-Prn & Nasal Convexity \\
\hline $\mathrm{Pg}-\mathrm{T}$ & Mandibular sagittal plane depth & $\mathrm{Go}_{\mathbf{r}}-\mathrm{Pg}-\mathrm{Go}_{\mathrm{I}}$ & Mandibular convexity \\
\hline Pg-Go & Mandibular body length & $\mathrm{T}_{\mathrm{r}}-\mathrm{Go}_{\mathrm{r}}-\mathrm{Pg}$ & Right mandibular angle \\
\hline T-Go & Mandibular ramus length & $\mathrm{T}_{1}-\mathrm{Go}_{1}-\mathrm{Pg}$ & Left mandibular angle \\
\hline Ratio & Description & & \\
\hline T-Go/Sn-Pg & Posterior to anterior facial heights ratio & & \\
\hline
\end{tabular}

Custom computer programs were used to perform all calculations. In particular, from patients measurements, $z$ score values were obtained subtracting the average values of reference subjects and dividing by their standard deviation $[25,26]$.

For patients younger than 18 years of age we used sex and age matched control subjects with an age span of two years compared to the patient's age, while we matched older patients with reference subjects of larger age intervals (18-30 years and 31-40 years) [27]. Subsequently, the average $z$ scores and their standard deviations were calculated for all measurements.

\section{Results}

Table 4 reports the descriptive statistics of the $z$ scores calculated for linear distances (9 facial measurements) and the facial ratio; table 5 reports the descriptive statistics of the $z$ scores calculated for angle measurements (9 facial angles).

Considering that by definition the average $z$ score of controls is 0 and its standard deviation is 1 , we focused on those mean patient $z$ scores that differed 1.5 SD or more from the control values.

Table 4. Descriptive statistics of the z scores calculated for linear distances and ratio. Measurements differing 1.5 SD or more from the reference values are marked with *.

\begin{tabular}{|l|l|l|l|l|l|l|l|l|l|l|}
\hline & $\mathrm{Ex}_{\mathrm{r}}-\mathrm{Ex} \mathrm{x}_{\mathrm{I}}$ & $\mathrm{T}_{\mathrm{r}}-\mathrm{T}_{1}$ & $\mathrm{Go}_{\mathrm{r}}-\mathrm{Go}_{1}$ & $\mathrm{Tr}-\mathrm{N}$ & $\mathrm{N}-\mathrm{Sn}$ & $\mathrm{Sn}-\mathrm{Pg}$ & $\mathrm{Pg}-\mathrm{T}$ & $\mathrm{Pg}-\mathrm{Go}$ & $\mathrm{T}-\mathrm{Go}$ & $\mathrm{T}-\mathrm{Go} / \mathrm{Sn}-\mathrm{Pg}$ \\
\hline Mean & $-1.7^{*}$ & -0.5 & 0.3 & 0.3 & 0.7 & 0.3 & $-1.8^{*}$ & $1.8^{*}$ & $-2^{*}$ & $-1.7^{*}$ \\
\hline SD & 1.1 & 0.8 & 1 & 1.2 & 1.4 & 1.2 & 1.1 & 0.6 & 1 & 1.2 \\
\hline Min & -3.4 & -1.5 & -1.4 & -0.9 & -1.4 & -0.9 & -3.3 & 1.1 & -3.1 & -3.3 \\
\hline Max & -0.2 & 0.8 & 1.7 & 2.7 & 1.7 & 2.7 & -0.2 & 2.7 & -0.4 & 0 \\
\hline
\end{tabular}

Table 5: Descriptive statistics of the z scores calculated for angles. Measurements differing 1.5 SD or more from the reference values are marked with *.

\begin{tabular}{|l|l|l|l|l|l|l|l|l|l|}
\hline & $\mathrm{N}-\mathrm{Sn}-\mathrm{Pg}$ & $\mathrm{SI}-\mathrm{N}-\mathrm{Sn}$ & $\mathrm{T}_{\mathrm{r}}-\mathrm{N}-\mathrm{T}_{1}$ & $\mathrm{~T}_{\mathrm{r}}-\mathrm{Prn}-\mathrm{T}_{1}$ & $\mathrm{~T}_{\mathrm{r}}-\mathrm{Pg}-\mathrm{T}_{1}$ & $\mathrm{Go}_{r}-\mathrm{Pg}-\mathrm{Go}_{\mid}$ & $\mathrm{T}_{\mathrm{r}}-\mathrm{Go}_{\mathrm{r}}-\mathrm{Pg}$ & $\mathrm{T}_{1}-\mathrm{Go}-\mathrm{Pg}$ & $\mathrm{Sn}-\mathrm{N}-\mathrm{Prn}$ \\
\hline Mean & -0.7 & 0.5 & 0 & 0.3 & 1.4 & $-1.7^{*}$ & $-2.2^{*}$ & $-1.7^{*}$ & -0.4 \\
\hline SD & 0.3 & 0.6 & 0.8 & 0.8 & 1.2 & 0.6 & 1.3 & 1 & 0.9 \\
\hline Min & -1.1 & -0.3 & -1.2 & -0.5 & -0.2 & -2.4 & -3.9 & -3.1 & -1.7 \\
\hline Max & 0.3 & 1.4 & 0.9 & 1.7 & 2.6 & -0.9 & -0.8 & -0.4 & 0.8 \\
\hline
\end{tabular}

In comparison with reference subjects, on average Glut-1DS patients had reduced biocular width and altered mandibular dimensions. In particular, the largest reduction was observed in the length of the mandibular ramus, while mandibular body length was increased. Mandibular depth in the sagittal plane, and the ratio between the posterior and anterior facial heights, were also reduced.

For what concerns angles, GLUT-1DS patients had a reduced mandibular convexity in the horizontal plane and smaller right and left gonial angles than reference subjects.

For both distances and angles, no apparent differences were found between children and adults, who had similar patterns of discrepancies vs. their control group. We analysed only one male patient (patient \#7), and thence no sex comparisons can be made. 
In general, the patient that differed more from reference values, both for facial distances and for angular measurements, was a girl of 3 years of age (patient \#6). In contrast, the patient who was less distant from reference values was a 18-years-old woman (patient \#2). As an example, figure 2 shows a comparison between patient \#6 and her group of 50 reference subjects paired for ethnicity, gender and age. The altered mandibular dimensions can be easily appreciated together with the reduced gonial angles.
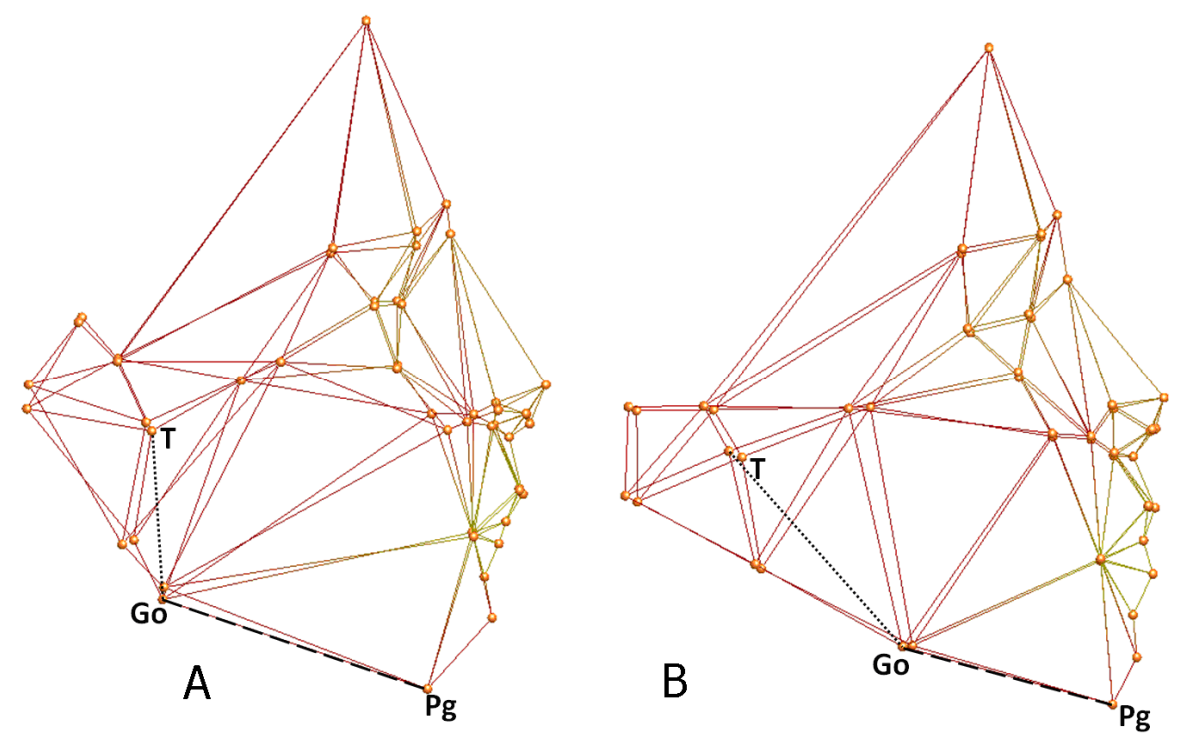

Fig. 2. Example of facial reconstruction of A) a 3 years old Glut-1DS patient and, B) the average of her 50 reference subjects; $\mathbf{T}-\mathbf{G o}=$ ramus of the mandible; $\mathbf{G o}-\mathbf{P g}=$ mandibular body.

\section{Discussion}

Anthropometry plays a key role in morphological and morphometric analysis of patients affected by different syndromes. Indeed, anthropometry is safe, non invasive and it can be easily performed, allowing the comparison between patients and control subjects, matched for ethnicity, gender and age $[22,26]$.

Among the various instruments and methods used for facial anthropometry, stereophotogrammetric systems are among the most suitable for a highly defined reproduction of three-dimensional facial morphology, both in healthy subjects and in patients $[23,24,28]$. Stereophotogrammetry has proved to be reliable, precise and repeatable, with a negligible error due to the imaging system [24]. Moreover, since the acquisition time is very short, these systems can also be used with children, not completely collaborative patients and people with a certain degree of mental retardation, such as Glut-1DS patients $[23,28]$.

All these qualities of stereophotogrammetric imaging make it the best choice for investigating facial features to find "soft" morphological markers that can be used to facilitate syndrome diagnosis even on a longitudinal base.

The current pilot study started from the clinical description of mandibular alterations in Glut-1DS patients, that are reported to possess a more prominent mandible and a retrognathic maxilla [8]. A small group of patients was therefore recruited and their facial dimensions and angles compared to those obtained in reference persons by using $z$ scores. $Z$ scores values (mean value and its standard deviation) are well suitable for morphometric analyses, and they are widely used in clinical anthropometry to assess single patients. For example, fetal ultrasonographic dimensions can be compared with those obtained in the reference population to estimate the probability of chromosomal disorders and better direct further, more complex clinical investigations [17,29].

The current data show that Glut-1DS patients have a set of common facial alterations from the reference population; most of the anomalies were found in the mandible, thus corroborating clinical reports [8]. Unfortunately, the lack of previous quantitative investigations on this topic prevents any general conclusion about the actual "typical" face of these patients. Only the reduced biocular width can be related to the cranial alterations previously reported in literature [12]. Nonetheless, the findings are promising, and they may be of help for an early diagnosis, considering that the facial features can be easily observed during a general medical inspection. 
In conclusion, the current group of Glut1-DS patients has a reduced biocular width alongside with a reduced mandibular convexity in the horizontal plane with a more anterior chin. Their mandibular body is longer but the rami are shorter, with a reduced gonial angle. No specific age-related differences were observed, but the reduced number of patients impedes any definitive assertion on the topic.

Data can be of great interest to improve the diagnosis of this syndrome and to allow longitudinal evaluations of facial morphology in a safe and not invasive way. In order to better describe the facial morphology of Glut1-DS patients, further evaluations on a larger sample are mandatory, together with a detailed assessment of other facial dimensions and characteristics.

\section{References}

[1] OMIM, http://omim.org/entry/606777, accessed on 10 June 2015.

[2] DC. De Vivo et al, "Defective glucose transport across the blood brain barrier as a cause of persistent hypoglicorrachia, seizures, and developmental delay", in New England Journal of Medicine, Vol. 325, 1991, pp. 703-709, http://dx.doi.org/10.1056/NEJM199109053251006.

[3] J. Klepper and B. Leiendecker, "GLUT-1 deficiency syndrome - 2007 update", in Developmental Medicine \& Child Neurology, Vol. 49, No. 9, 2007, pp. 707-716, http://dx.doi.org/10.1111/j.14698749.2007.00707.x.

[4] K. Brockmann et al, "Autosomal Dominant Glut-1 Deficiency Syndrome and Familial Epilepsy", in Annals of Neurology, Vol. 50, No. 4, 2001, pp. 476-485, http://dx.doi.org/10.1002.ana.1222.

[5] J. Klepper and T. Voit, "Facilitated glucose transporter protein type 1 (GLUT1) deficiency syndrome: impaired glucose transport into brain - a review", in European Journal of Paediatry, Vol. 161, 2002, pp. 295-304, http://dx.doi.org/10.1007/s00431-002-0939-3.

[6] R. Duelli and W. Kuschinsky, "Brain Glucose Transporters: Relationship to Local Energy Demand", Physiology, Vol.16, No. 2, 2001, pp.71-76.

[7] J. Klepper et al, "Autosomal dominant transmission of GLUT1 Deficiency", in Human Molecular Genetics, Vol. 10, No. 1, 2001, p. 63, http://dx.doi.org/10.1093/hmg/10.1.63.

[8] V. De Giorgis et al, "Sporadic and familial glut1ds Italian patients: A wide clinical variability", in Seizure, Vol. 24, 2015, pp. 28-32, http://dx.doi.org/10.1016/j.seizure.2014.11.009.

[9] N. Brockmann, "The expanding phenotype of GLUT1-deficiency syndrome", in Brain \& Development, Vol. 31, No. 7, 2009, pp. 545-552, http://dx.doi.org/10.1016/j.braindev.2009.02.008.

[10] A. Verrotti et al, "Glut1 deficiency: when to suspect and how to diagnose?", in European Journal of Pediatric Neurology, Vol.16, No. 1, 2012, pp. 3-9, http://dx.doi.org/10.1016/i.eipn.2011.09.005.

[11] PR. Kollros and BA. Konkle, "A candidate mutation in the GLUT-1 gene in a patient with glucose transporter dysfunction at the blood-brain barrier", in Annals of Neurology, Vol. 32, No. 1992, p. 445 http://dx.doi.org/10.1002/ana.410320329.

[12] V. De Giorgis and P. Veggiotti, "GLUT1 deficiency syndrome 2013: Current state of the art", in Seizure, Vol. 22, No. 10, 2013, pp. 803-811, http://dx.doi.org/10.1016/j.seizure.2013.07.003.

[13] JE. Allanson et al, "The face of Smith-Magenis syndrome: a subjective and objective study", in Journal of Medical Genetics, Vol. 36, No. 5, 1999, pp. 394-397, http://dx.doi.org/10.1136/img.36.5.394.

[14] TS. Douglas et al, "Eye feature extraction for diagnosing the facial phenotype associated with fetal alcohol syndrome", in Medical \& Biological Engineering \& Computing, Vol. 41, No. 1, 2003, pp. 101-106.

[15] L. Guyot et al, "Craniofacial anthropometric analysis in patients with 22q11 microdeletion", in American Journal of Medical Genetics, Vol. 100, No. 1, 2001, pp. 1-8, http://dx.doi.org/10.1002/1096-8628(20010415)100:1<1::AID-AJMG1206>3.0.CO;2-6.

[16] C. Sforza et al, "Morphometry of the ear in Down's syndrome subjects. A three-dimensional computerized assessment", in International Journal of Oral and Maxillofacial Surgery, Vol. 34, No. 5, 2005, pp. 480-486, http://dx.doi.org/10.1016/j.ijom.2004.10.005.

[17] U. Chitkara et al, "Fetal ear length measurement: a useful predictor of aneuploidy?", in Ultrasounds in Obstetrics and Gynecology, Vol. 19, No. 2, 2002, pp. 131-135, http://dx.doi.org/10.1046/j.0960-7692.2001.00558.x.

[18] C. Sforza et al, "Soft tissue facial morphometry in subjects with Moebius syndrome", in European Journal of Oral Sciences, Vol. 117, No. 6, 2009, pp. 695-703, http://dx.doi.org/10.1016/j.ijom.2004.10.005.

[19] C. Sforza et al, "Variation in facial soft tissues of Italian Individuals with ectodermal dysplasia", in Cleft Palate Craniofacial Journal, Vol. 41, No. 3, 2004; pp. 262-267, http://dx.doi.org/10.1597/03033.1. 
[20] VF. Ferrario et al, "Three-dimensional facial morphometric assessment of soft-tissue changes after orthognathic surgery", in Oral Surgery Oral Medicine Oral Pathology Oral Radiology and Endodontics, Vol. 88, No. 5, 1999, pp. 549-556, http://dx.doi.org/10.1016/S1079-2104(99)700843 .

[21] C. Sforza et al, "Three-dimensional facial morphometry in skeletal Class III patients. A noninvasive study of soft-tissue changes before and after orthognathic surgery", in British Journal of Oral and Maxillofacial Surgery, Vol. 45, No. 2, 2005, pp. 138-144, http://dx.doi.org/10.1016/i.bjoms.2005.12.013.

[22] C. Sforza et al, "Three dimensional facial morphometry: from anthropometry to digital morphology", in Handbook of Anthropometry, Physical Measures of Human Form in Health and Disease. V.R. Preedy (Ed.), Springer Science+Business Media, LLC; Ch. 32, pp. 611-624, 2012; http://dx.doi.org/10.1007/978-1-4419-1788-1 32.

[23] C. Sforza et al, "Soft- and hard-tissue facial anthropometry in three dimensions: what's new", in Journal of Anthropological Sciences, Vol. 91, 2013, pp. 59-84, http://dx.doi.org/10.4436/JASS.91007.

[24] M. De Menezes et al, "Accuracy and reproducibility of a 3-Dimensional stereophotogrammetric imaging system", in Journal of Oral and Maxillofacial Surgery, Vol. 68, No. 9, 2010, pp. 21292135, http://dx.doi.org/10.1016/j.joms.2009.09.036.

[25] RE. Ward et al, "Quantitative approach to identifying abnormal variation in the human face exemplified by a study of 278 individual with five craniofacial syndromes", in American Journal of Medical Genetics, Vol. 91, No. 1, 2000, pp. 1-8, http://dx.doi.org10.1002/(SICl)10968628(20000306)91:1<8::AID-AJMG2>3.0.CO;2-\#.

[26] C. Sforza et al, "A quantitative three dimensional assessment of abnormal variations in the facial soft tissues of individuals with Down syndrome", in Cleft Palate Craniofacial Journal, Vol. 42, No. 4, 2005, pp. 410-416, http://dx.doi.org/10.1597/04-005.1.

[27] C. Sforza et al, "Abnormal variations in the facial soft tissues of individuals with Down syndrome: Sudan versus Italy", in Cleft Palate Craniofacial Journal, 2014 Oct 2. [Epub ahead of print], http://dx.doi.org/10.1597/14-082.

[28] K. Aldridge et al, "Precision and error of three-dimensional phenotypic measures acquired from 3dMD photogrammetric images" in American Journal of Medical Genetics, Vol. 138A, No. 3, 2007, pp. 247-253, http://dx.doi.org/10.1002/ajmg.a.30959.

[29] NM. Roelfsema et al, "Craniofacial variability index in utero: a three-dimensional ultrasound study", in Ultrasounds in Obstetrics and Gynecology, Vol. 29, 2007, pp. 258-264, http://dx.doi.org/10.1002/uog.3904. 